\title{
IMPLEMENTASI METODE NORTH WEST CORNER DAN STEPPING STONE PADA PENGIRIMAN BARANG GALERI BIMASAKTI
}

\author{
Yekti Asmoro Kanthi ${ }^{1}$, Bagus Kristomoyo Kristanto ${ }^{2}$ \\ ${ }^{1}$ Manajemen Informatika, STIKI Malang, ${ }^{2}$ Teknik Informatika, STIKI Malang \\ Email: ${ }^{1}$ yektiasmoro@stiki.ac.id, ${ }^{2}$ bagus.kristanto@stiki.ac.id \\ *Penulis Korespondensi
}

(Naskah masuk: 9 Januari 2019, diterima untuk diterbitkan: 5 Mei 2019)

\begin{abstract}
Abstrak
Permasalahan transportasi pada umumnya berhubungan dengan distribusi produk dari berbagai sumber ke beberapa lokasi penjualan. Pendistribusian memegang peran penting karena tanpa adanya pola distribusi yang tepat, maka proses ini dapat memakan biaya tinggi dan mengakibatkan pemborosan dari segi waktu, jarak dan tenaga. Metode North-west Corner dan metode Stepping Stone merupakan salah satu metode yang digunakan untuk menyelesaikan proses trasnportasi yang menghasilkan biaya total dan biaya total optimum. Penelitian ini bertujuan untuk mengimplementasikan biaya tarnsportasi distribusi pengiriman barang pada Galeri Bimasakti menggunakan metode north-west corner dan metode stepping stone. Galeri Bimasakti merupakan salah satu usaha yang bergerak di bidang industri penjualan furniture dan memiliki pabrik di dua kota yaitu Jepara dan Sidoarjo serta memiliki tiga lokasi penjualan di Karangploso, Batu dan Malang. Metodologi penelitian yang digunakan adalah metode analisa dan metode perancangan, di mana dalam metode analisa yang digunakan terdiri dari metode studi kepustakaan, survei lapangan, dan wawancara dari proses bisnis yang sedang berjalan, sedangkan dalam metode perancangan menggunakan perancangan object berbasis desktop. Hasil yang ingin dicapai untuk memberikan fasilitas kepada Galeri Bimasakti berupa aplikasi perhitungan pendistribusi barang dari pabrik ke beberapa lokasi penjualan. Biaya pengiriman barang yang sudah terhitung dapat tersimpan dengan aman karena data biaya pengiriman barangnya tersimpan di system.
\end{abstract}

Kata kunci: pengiriman, North-west Corner, Stepping Stone.

\section{IMPLEMENTATION OF NORTH-WEST CORNER METHOD AND STEPPING STONE METHOD FOR SHIPPING GOODS TO THE BIMASAKTI GALLERY}

\begin{abstract}
Transportation problems generally relate to product distribution from various sources to several sales locations. Distribution have important effect because without good distribution design, it will be high-cost and inefficient time, distance and resource. The North-west Corner method and the Stepping Stone method are one of the methods used to solve and generate total costs and optimum total costs. This study aims to implement the distribution cost of shipping goods to the Bimasakti Gallery using the north-west corner method and the stepping stone method. Bimasakti Gallery is a business engaged in the furniture sales industry and has factories in two cities, Jepara and Sidoarjo and has three sales locations in Karangploso, Batu and Malang. The research methodology used are analysis and design method, analytical method used consists of library study methods, field surveys, and interviews of ongoing business processes, while design method used desktop-based object design. Expected Result from this study is providing an application to facilities the Bimasakti Gallery for calculate the distribution of goods from the factory to several sales locations. The cost of shipping goods that have been calculated can be stored safely because the data is stored in the system.
\end{abstract}

Keywords: shipping, North-west Corner, Stepping Stone

\section{PENDAHULUAN}

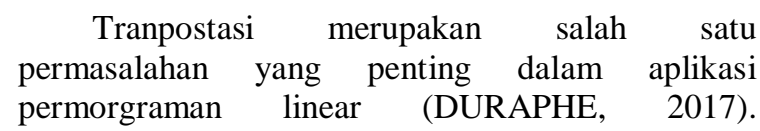

Transportasi adalah bentuk perpindahan manusia atau barang dari satu tempat ke tempat lainnya dengan menggunakan suatu alat yang digerakkan oleh manusia atau mesin. Masalah transportasi berhubungan dengan distribusi suatu produk tunggal 
dari beberapa sumber, dengan penawaran terbatas, menuju beberapa tujuan, dengan permintaan tertentu, pada biaya transport yang minimum. Karena hanya ada satu macam barang, suatu tempat tujuan dapat memenuhi permintaannya dari satu atau lebih sumber. Transportasi dikatakan seimbang jika total jumlah antara sumber dan tujuan sama. Sedangkan tidak seimbang jika sumber lebih besar dari tujuan atau jumlah sumber lebih kecil dari tujuan. Permasalahan tersebut diselesaikan pada batas waktu tertentu. Ketika sebuah masalah mempunyai variasi waktu, maka teknik riset operasi harus mampu menyelesaikan masalah tersebut secara dinamis (MULYONO, 2002)

Metode transportasi digunakan untuk mengatur distribusi dari sumber yang menyediakan produk ke tempat yang membutuhkan secara optimal. Ada beberapa metode untuk mencari solusi awal. Metode penyelesaian solusi awal ada 3 macam yaitu metode north west corner, metode least cost dan metode vogel. Sedangkan untuk solusi optimal ada 2 macam yaitu metode stepping stone dan metode MODI. Alokasi produk ini harus diatur sedemikian rupa karena terdapat perbedaan biayabiaya dari satu sumber ke suatu tempat tujuan yang berbeda-beda.

Persediaan atau penawaran (supply) maksimum pada setiap sumber dan permintaan (demand) minimum pada setiap fungsi tujuan. Distribusi ini dilakukan sedemikian rupa sehingga permintaan dari beberapa tempat tujuan dapat dipenuhi dari beberapa sumber, yang masing-masing dapat memiliki permintaan atau kapasitas yang berbeda. Alokasi ini dilakukan dengan mempertimbangkan biaya pengangkutan yang bervariasi karena jarak dan kondisi antara lokasi yang berbeda. Dengan menggunakan metode transportasi, dapat diperoleh suatu alokasi distribusi barang yang dapat meminimalkan total biaya transportasi (SUSANTA, 2010)

Industri mebel dan kerajinan dalam negeri berkontribusi cukup signifikan terhadap perekonomian nasional, dianggap memiliki nilai strategis secara ekonomis. Direktur Jendral Industri Kecil dan Menengah (IKM) Kementrian Perindustrian, Gati Wibawaningsih menyatakan bahwa Indoensia menargetkan nilai ekspor mebel dan kerajinan mengalami kenaikan mencapai sekitar dua miliar dolar AS pada 2018, dan mencapai 2,5 miliar dolar AS pada 2019. Pernyataan ini disampaikan seusai membuka "Launching Omah Mebel dan Kerajinan Koperasi Industri Mebel dan Kerajinan Solo Raya (KIMKAS)" di Solo.

Ekspor mebel dan kerajinan Indoensia pada tahun 2015 mencapai 1,21 miliar dolar AS, sedangkan pada tahun 2016 sebesar 1,04 miliar dolar AS. Penyebab penurunan diperkirakan karena beberapa hal antara lain ketersediaan pasokan bahan baku, adanya overlapping dari beberapa regulasi serta berkrangnya promosi produk. Berdasarkan data yang ada di Kementrian Perindustrian, pada tahun 2015 terdapat 21.643 unit usaha IKM dengan jumlah tenaga kerja mencapai 46.764 orang dan nilai investasi diperkirakan mencapai Rp. 5,8 triliun.

Dalam rangka penguatan sektor industry tersebut, Kementrain Perindustrian memiliki enam kebijakan prioritas industry nasional yaitu penguatan sumber daya manusia melalui penguatan vokasi industry, pendalaman struktur industry melallui penguatan rantai nilai industry, industry padat karya, dan orientasi ekspor, pengembangan IKM dengan platform digital melalui e-smart IKM, pengembangan industry berbasis SDA serta pengembangan perwilayahan industry. Pemerintah bertekad memacu pengembangan industry mebel dan kerajinan nasional melalui penguatan koordinasi di lintas kementrian dan lembaga. Langkah sinergis yang dilakukan, antara lain untuk menjamin ketersediaan bahan baku, memberikan insentif untuk meningkatkan ekspor dan mendorong investasi di sektor yang berbasis hasil hutan tersebut. Serta meningkatkan koordinasi dan kerjasama seluruh stakeholder agar terus berupaya mengisi potensi peluang pasar ekspor dan dalam negeri yang cuku luas.

Galeri Mebel Bimasakti merupakan salah galeri yang menyediakan furniture dari berbagai macam kayu baik kayu jati maupun kayu mahoni. Produksinya dibuat oleh perajin-perajin terbaik di Jepara dan dibuat dari bahan-bahan yang berkualitas. Galeri ini berdiri pada tahun 2000, dimulai dari usaha kecil dalam satu kota kemudian berkembang ke 3 kota sebagai pasar sasaran yaitu Karangploso, Batu dan Malang. Galeri ini memiliki dua pabrik yang berada di kota Malang dan Sidoarjo.

Penelitian ini menerapkan penggunaan metode transportasi untuk menghitung biaya pengiriman barang dari beberapa lokasi sumber ke beberapa lokasi tujuan. Adapun tujuan dari penggunaan metode transportasi sebagai upaya untuk pendistribusian barang agar supply dari beberapa sumber dapat dilakukan secara efektif dan biaya murah ke beberapa tempat tujuan. Sehubungan dengan hal tersebut, permasalahan yang akan dikaji selanjutnya adalah penggunaan metode transportasi North West Corner sebagai salah satu teknik solusi awal dan metode transportasi Stepping Stone sebagai salah satu teknik optimum dalam pendistribusian barang.

\section{METODE PENELITIAN}

\subsection{Penelitian Terdahulu}

Ada beberapa penelitian terdahulu yang dianggap relevan dengan topic penelitian ini. Penelitian yang dilakukan oleh (FAHMI, 2017) mengenai penerapan metode stepping stone untuk transportasi pengiriman barang pada jasa ekspedisi barang. Penelitian ini bertujuan untuk merencanakan pengiriman sesuatu dari sumber-sumber ke tujuan sedemikian rupa untuk meminimumkan total biaya 
transportasi. Hasil dari penelitian tersebut penerapan metode stepping stone sangat cocok digunakan untuk transportasi pengiriman barang karena biata yang dihasilkan optimal. Dalam penelitian tersebut juga dibangun suatu aplikasi pengiriman barang sehingga proses transportasi lebih optimal.

Penelitian kedua dilakukan oleh (ISWANTI, et al., 2016) tentang penerapan aplikasi transportasi pengiriman barang menggunakan metode least cost dan MODI (modified distribution) pada CV. Nihta Cargo Express. Penelitian ini bertujuan untuk menerappkan biaya transportasi distribusi pengiriman barang pada CV Nihta Cargo Express dengan menggunakan metode least cost dan MODI (modified distribution). Hal ini dilakukan agar perusahaan dapat mengetahui biaya pengiriman barang yang optimal. Hasil dari penelitian tersebut yaitu penerapan metode least cost pada pemecahan awalnya dan pemecahan di optimalkan menggunakan metode modified distribution (MODI) dengan menguraikan biatya proses pengiriman barang dari suatu sistem informasi yang utuh ke dalam bagian-bagian komponennya sehingga permasalahan dapat dievaluasi.

Penelitian ketiga dilakukan oleh (ROSTA \& TANNADY, 2012) tentang pendistribusian produk yang optimal dengan metode transportasi. Penelitian ini bertujuan untuk mengetahui biaya transportasi dan kapasitas yang paling optimal menggunakan metode VAM (vogel approximation) dan metode stepping stone. Hasil dari penelitian ini yaitu diperoleh hasil yang paling optimal dnegan satu tahapan iterasi, dimana tabel transportasi harus menggunakan dummy karena kapasitas gudang yang tidak sama dengan kapasitas pabrik. Selain itu, juga diketahui bahwa perhitungan solusi awal menggunakan metode VAM, dapat mempersingkat waktu yang dibutuhkan untuk menghitung biaya. Metode ini tidak memerlukan banyak tahapan iterasi dibanding metode lain, yaitu metode least cost dan metode north west corner sehingga untuk mendapatkan solusi optimal dengan metode stepping stone, waktu yang diperlukan dapat lebih singkat dibandingkan dengan metode lainnya.

Penelitian selanjutnya dilakukan oleh (IRWAN \& YUNIRAL, 2016) tentang pendistribusian produk yang optimal dengan metode transportasi. Penelitian ini bertujuan untuk mengetahui biaya transportasi dan kapasitas yang paling optimal menggunakan metode VAM (vogel approximation) dan metode stepping stone. Hasil dari penelitian ini yaitu diperoleh hasil yang paling optimal dengan satu tahapan iterasi, dimana tabel transportasi harus menggunakan dummy karena kapasitas gudang yang tidak sama dengan kapasitas pabrik. Selain itu, juga diketahui bahwa perhitungan solusi awal menggunakan metode VAM, dapat mempersingkat waktu yang dibutuhkan untuk menghitung biaya. Metode ini tidak memerlukan banyak tahapan iterasi dibanding metode lain, yaitu metode least cost dan metode north west corner sehingga untuk mendapatkan solusi optimal dengan metode stepping stone, waktu yang diperlukan dapat lebih singkat dibandingkan dengan metode lainnya.

\subsection{Prosedur Penelitian}

Prosedur penelitian ada 3 tahapan yaitu pengumpulan data, pemilihan data dan analisis serta pembahasan yang dapat dilihat pada gambar 1 berikut.

\subsection{Tinjauan Pustaka}

Metode transportasi merupakan suatu metode yang digunakan untuk mengatur distribusi suatu produk (barang-barang) dari sumber-sumber yang menyediakan produk (misalnya pabrik) ke tempattempat tujuan (misalnya gudang) secara optimal. Tujuan dari model ini adalah menentukan jumlah yang harus dikirim dari setiap sumber ke setiap tujuan sedemikian rupa dengan total biaya transportasi minimum. (TAMIN, 2000)

Data yang dibutuhkan dalam metode transportasi yaitu tingkat penawaran di setiap sumber dan jumlah permintaan di setiap tujuan dan biaya transportasi per unit barang dari setiap sumber ke setiap tujuan. Ciri-ciri penggunaan metode transportasi yaitu :

1. Terdapat sejumlah smber dan tujuan tertentu

2. Kuantitas komoditi / barang yang didistribusikan dari setiap sumber dan yang diminta oleh setiap tujuan besarnya tertentu.

3. Komoditi yang dikirim dari suatu sumber ke suatu tujuan besarnya sesuai dengan permintaan dan kapasitas sumber

4. Jenis komoditi yang didistribusikan sama

5. Biaya pengangkutan komoditi dari suatu sumber ke suatu tujuan besarnya tertentu.

(TAHA, 2004)

Model transportasi pada saat dikenali pertama kali diselesaikan dengan cara manual menggunakan algoritma yang dikenal sebagai algoritma transportasi. Langkah-langkah penyelesaian metode transportasi yaitu :

1. Diagnosis masalah dimulai dengan pengenalan sumber, tujuan, parameter, dan variabel

2. Seluruh informasi tersebut kemudian dituangkan ke dalam matriks tranaposrtasi. Dalam hal ini, ketentuannya yaitu :

a. Bila kapasitas seluruh sumber lebih besar dari permintaan seluruh tujuan maka sebuah kolom (dummy) perlu ditambahkan untuk menampung kelebihan kapasitas itu

b. Bila kapasitas seluruh sumber lebih kecil dari seluruh permintaan tujuan maka sebuha baris perlu ditambahkan untuk menyediakan kapasitas semu yang akan memenuhi kebelihan permintaan itu. Jelas sekali bahwa kelebihan permintaan itu tidak bisa dipenuhi. 
3. Setelah matriks transportasi terbentu kemudian dimulai menyusun tabel awal. Algoritma transportasi mengenal tiga macam metode untuk menyusun tabel awal yaitu :

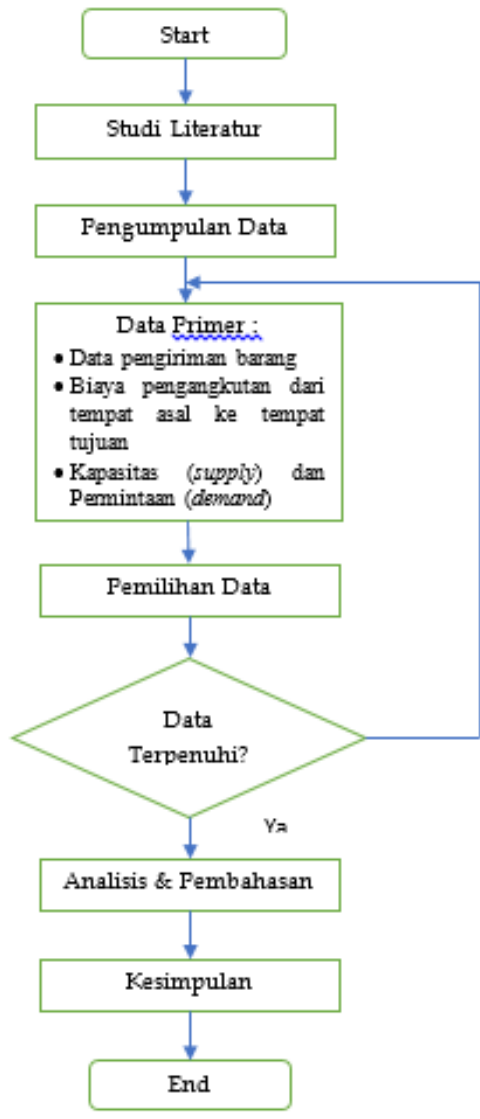

a. Metode sudut barat laut (north west corner)

b. Metode biaya terkecil (least cost)

c. Metode VAM (Vogel Approximation)

Gambar 1. Prosedur Penelitian

Ketiga model tersebut masing-masing berfungsi untuk menentukan alokasi distribusi awal yang akan membuat seluruh kapasitas sumber teralokasi ke seluruh tujuan

4. Setelah penyusunan tabel awal selsai maka sebagai langkah selanjutnya adalah pengujian optimalitas tabel untuk mengetahui apakah biaya distribusi total telah minimum. Secara matematis, pengujian ini dilakukan untuk menjamin bahwa nilai fungsi tujuan minimum telah tercapai. Ada dua macam pengujian optimalitas algoritma transportasi yaitu Metode Stepping Stone dan MODI (Modified Distribution).

5. Langkah terakhir adalah revisi tabel bila dalam langkah keempat terbukti bahwa tabel belum optimal atau biaya distribusi total masih mungkin diturunkan lagi. Dengan demikian, jelas sekali bahwa langkah kelima ini tidak akan dilakukan apabila padalangkah keempat telah membuktikan bahwa tabel telah optimal. Dalam penyelesaian persoalan transportasi, harus dilakukan langkah-langkah sebagai berikut :

a. Tentukan solusi feasible awal b. Tentukan entering variable dari variabelvariabel non basis. Bila semua variabel sudah memenuhi kondisi optimum, maka berhenti. Bila belum lanjutkan langkah.

c. Tentukan leaving variable diantara variabel-variabel basis yang ada, kemudian hitung solusi baru.

d. Kembali ke langkah b.

(SISWANTO, 2007)

\subsection{Metode North-west Corner}

Metode sudut barat laut adalah metode yang paling sederhana untuk mencari solusi awal dari transportasi. Metode ini didasarkan pada aturan atau pengalokasian normative dari persediaan dan kebutuhan sumber dalam suatu matriks transportasi tanpa perhitungan besar-besaran ekonomis. Aturan normative tersebut yaitu membebani semaksimal mungkin sampai batas maksimum persediaan atau kebutuhan (mana yang tercapai terlebih dahulu) pada matriks alokasi ujung kiri atas terus menuju ke kanan bawah sedemikian hingga seluruh kebutuhan akan sumber dapat terpenuhi. Langkah-langkah metode ini sebagai berikut : 
a. Mulai dari pojok barat laut tabel dan alokasikan sebanyak mungkin tanpa menyimpang dari kendala penawaran atau permintaan

b. Penawaran pada asal barang 1 atau permintaan pada tujuan barang 1 akan habis, sehingga tidak ada barang lagi yang dapat dialokasikan ke kolom atau baris yang telah dihabiskan. Kemudian alokasikan sebanyak mungkin kekotak didekatnya pada baris atau kolom yang dapat dihilangkan. Jika kolom atau baris telah dihabiskan, pindahlah secara diagonal kekotak berikutnya.

c. Dengan cara yang sama proses dilanjutkan sampai semua penawaran telah dihabiskan dengan keperluan permintaan telah dipenuhi.

d. Kemudian dicari nilai biaya minimum dengan menjumlahkan seluruh alokasi yang ada dengan cara mengalikan alokasi dengan biaya transportasi

(RANGKUTI, 2013)

\subsection{Metode Stepping Stone}

Metode stepping stone adalah metode yang digunakan untuk menghaislkan pemecahan layak bagi permasalahan transportasi dengan biaya-biaya operasi (biaya pabrik dan biaya transportasi) sehingga mendapatkan biaya pengiriman relative. Metode ini dilakukan dengan membuat siklus-siklus pengendalian alokasi ke kotak-kotak yang tidak terisi (variabel non baris). Sebelumnya diperiksa dulu apakah jumlah kotak yang terisi pada solusi awal telah memenuhi jumlah $(m+n+1)$, bila belum maka dilakukan penambahan jumlah kotak yang terisi dengan cara memberikan alokasi nol pada kotak yang kosong. Adapun tujuan dari jalur ini adalah untuk mempertahakan kendala penawaran dan permintaan sambil melakukan alokasi ulang barang ke suatu kotak kosong. Semua kotak kosong dievaluasi dengan cara yang sama untuk menentukan apakah kotak tersebut dapat menurunkan biaya dank arena itu menjadi calon entering variable. Entering variable adalah kotak kosong yang mempunyai nilai negative pada jalur penambahan dan pengurungan biaya.

Aturan siklus dari metode stepping stone sebagai berikut :

a. Suatu siklus perubahan pengalokasian tidak boleh mengubah nilai penawaran dan permintaan

b. Dalam satu siklus hanya noleh terdapat satu kotak kosong (variabel non baris) yang terlibat

c. Suatu siklus berawal dan berakhir pada kotak yang sama

d. Hanya boleh ada 2 kotak yang berturutan yang terlibat terletak pada baris atau kolom yang sama.

Jadi, metode stepping stone pengujiannya didasarkan pada hasil perhitungan perubahan biaya dari siklus untuk mencoba mengalokasikan pada kotak yang kosong (variabel non baris).

(PATEL, et al., 2017)

\section{HASIL DAN PEMBAHASAN}

\subsection{Perhitungan Data dengan Metode North-west Corner dan Stepping Stone}

Berdasarkan hasil observasi lapang diperoleh suatu data yang menjelaskan tentang biaya transportasi pengiriman barang dari masing-masing pabrik (sumber) ke maisng-masing kota tujuan. Selain itu, juga dibutuhkan tentang persediaan barang dari masing-masing pabrik dan jumlah permintaan barang dari masing masing kota. Hasil data penelitian dapat dilihat pada tabel 1 berikut.

Tabel 1. Data Hasil Penelitian Galeri Bimasakti

\begin{tabular}{ccccc}
\hline Pabrik & \multicolumn{3}{c}{ Pasar Sasaran } & Supply \\
\cline { 2 - 4 } & $\begin{array}{c}\text { I } \\
\text { (Karangploso) }\end{array}$ & $\begin{array}{c}\text { II } \\
\text { (Batu) }\end{array}$ & $\begin{array}{c}\text { III } \\
\text { (Malang) }\end{array}$ & \\
\hline $\begin{array}{c}\text { A } \\
\text { (Jepara) }\end{array}$ & 2.700 .000 & 2.500 .000 & 3.100 .000 & 34 \\
\hline $\begin{array}{c}\text { B } \\
\text { (Sidoarjo) }\end{array}$ & 1.700 .000 & 1.900 .000 & 1.600 .000 & 19 \\
\hline Demand & 31 & & & \\
\hline
\end{tabular}

Dari tabel 1, maka dapat dihitung terlebih dahulu menggunakan metode north west corner sebagai solusi awal dari jumlah biaya transportasi yang disajikan pada tabel 2 berikut.

Tabel 2. Hasil Perhitungan Data dengan Metode North West Corner

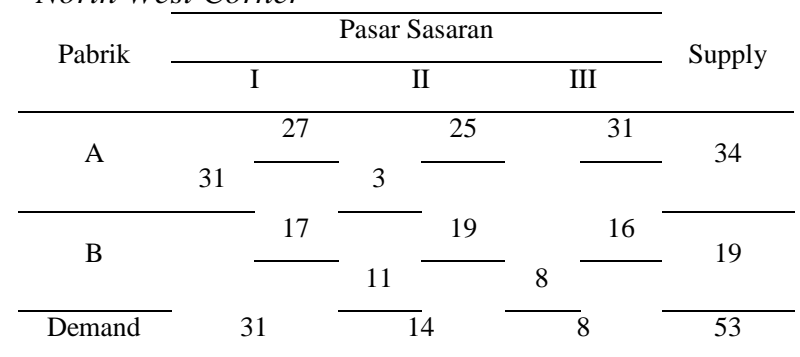

Dari perhitungan pada table 2 didapatkan hasil biaya total sebagai berikut

$$
\begin{aligned}
\text { biayatotal }= & (31 \times 2.700 .000)+(3 \times 2.500 .000)+ \\
& (11 \times 1.900 .000)+(8 \times 1.600 .000)=124.900 .000
\end{aligned}
$$

Langkah selanjutnya, untuk mendapatkan solusi optimum maka hasil perhitungan menggunakan metode north west corner dilanjutkan dengan metode stepping stone yang ditunjukkan pada tabel 3 berikut.

Tabel 3. Hasil Perhitungan Data dengan Metode Stepping Stone 


\begin{tabular}{|c|c|c|c|c|c|}
\hline \multirow{2}{*}{ Pabrik } & \multicolumn{4}{|c|}{ Pasar Sasaran } & \multirow{2}{*}{ Supply } \\
\hline & I & II & \multicolumn{2}{|c|}{ III } & \\
\hline A & 27 & 25 & & 31 & 34 \\
\hline B & 17 & 13 & & 10 & 19 \\
\hline Demand & 31 & 14 & & & 53 \\
\hline
\end{tabular}

$\mathrm{AIII}=\mathrm{AIII}-\mathrm{AII}+\mathrm{BII}-\mathrm{BIII}=31-25+19-16=9$ $\mathrm{BI}=\mathrm{BI}-\mathrm{BII}+\mathrm{AII}-\mathrm{AI}=17-19+25-27=-4$

Hasil tersebut belum optimal karena masih ada nilai minus yaitu (-4), maka akan dilanjutkan iterasi ke-2 dari metode stepping stone yang dapat dilihat pada tabel 4.

Tabel 4. Iterasi ke-2 dari penyelesaian Metode Stepping Stone

\begin{tabular}{|c|c|c|c|c|c|c|}
\hline \multirow{2}{*}{ Pabrik } & \multicolumn{5}{|c|}{ Pasar Sasaran } & \multirow{2}{*}{ Supply } \\
\hline & & I & II & & III & \\
\hline \multirow{3}{*}{ A } & & 27 & & 25 & 31 & \multirow{3}{*}{34} \\
\hline & & - & + & & & \\
\hline & 28 & & 64 & & & \\
\hline \multirow{3}{*}{ B } & & 17 & & 19 & 16 & \multirow{3}{*}{19} \\
\hline & & +1 & - & - & & \\
\hline & 3 & & 8 & 8 & 8 & \\
\hline Demand & & 1 & 14 & & 8 & 53 \\
\hline
\end{tabular}

Karena sudah tidak ada lagi nilai yang negative, maka dapat ditentukan hasil yang paling optimum yaitu

$$
\begin{aligned}
\text { biayatotal }= & (28 \times 2.700 .000)+(3 \times 1.700 .000)+ \\
& (6 \times 2.500 .000)+(8 \times 1.900 .000)+ \\
& (8 \times 1.600 .000)=123.700 .000
\end{aligned}
$$

Jadi, biaya optimum yang dikeluarkan galeri bimasakti selama satu periode pengiriman sebesar Rp. 123.700.000,- dari masing-masing pabrik ke masing-masing pasar sasaran.

\subsection{Implementasi Program}

Tahap implementasi merupakan penerapan pembuatan program perhitungan biaya transportasi pada Galeri Bimasakti berbasis desktop. Pembuatan program berawal dari halaman login. Tampilan awal saat program ini dibuka yaitu halaman login yang memuat tentang username dan password. Setelah masuk ke halaman login, selanjutnya masuk ke halaman dashboard yang dapat dilihat pada gambar 2 berikut.

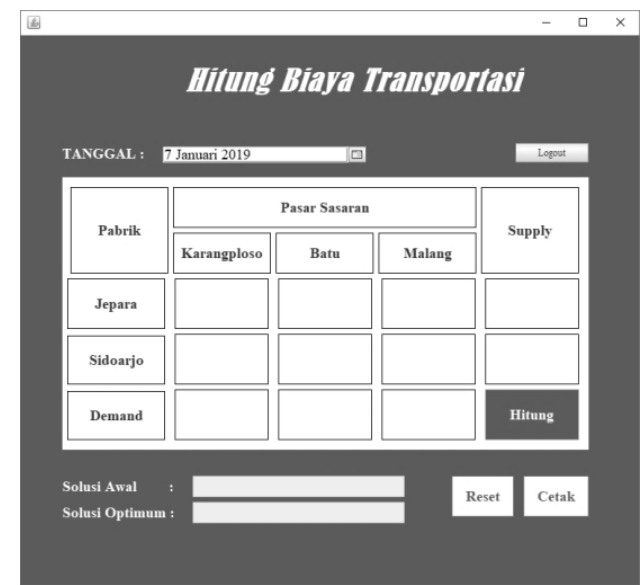

Gambar 2. Halaman Dashboard

Pada halaman perhitungan, user diwajibkan untuk memasukkan data-data yang dibutuhkan yaitu biaya-biaya transportasi yang diperlukan dari beberapa sumber ke beberapa tujuan. Halaman perhitungan dapat dilihat pada gambar 3 berikut.

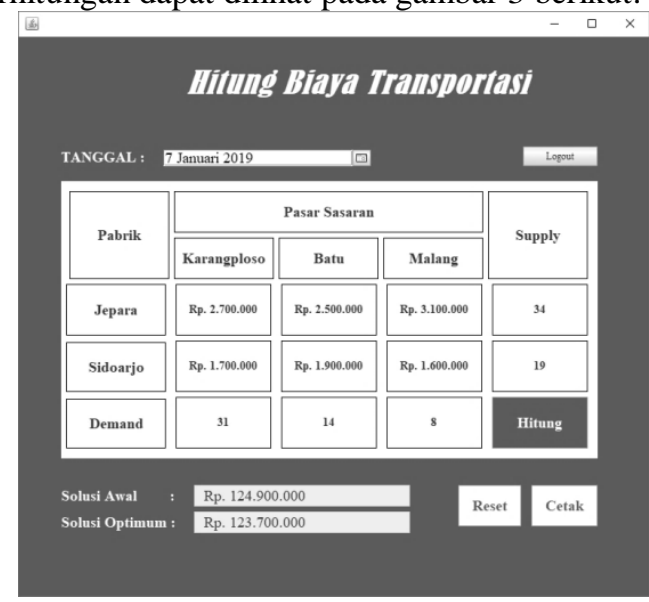

Gambar 3. Halaman Perhitungan

Setelah melalui proses input data dan perhitungan maka hasil perhitungan dapat di cetak. Output program hasil cetak dapat dilihat pada gambar 4 dan gambar 5 berikut.

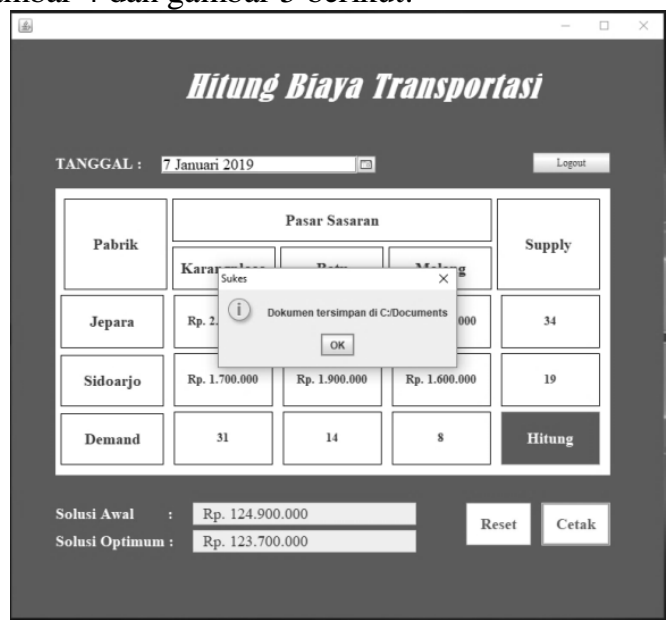

Gambar 4. Halaman permintaan cetak dokumen 


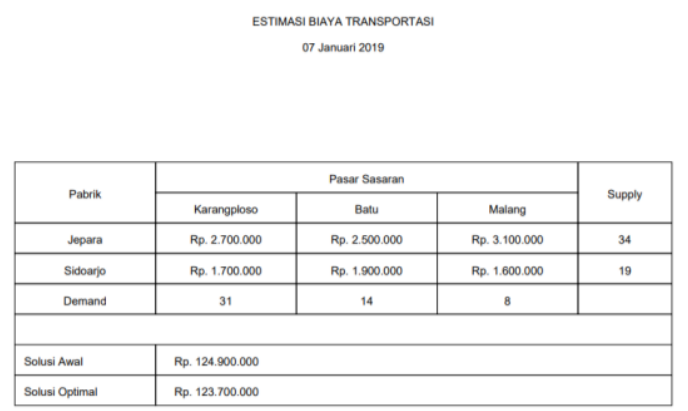

Gambar 5. Hasil cetak perhitungan

\section{KESIMPULAN}

Berdasarkan penelitian yang dilakukan dapat disimpulkan beberapa hal yaitu :

1. Hasil pengolahan data dengan perhitungan secara manual menggunakan metode northwest corner menghasilkan biaya total $\mathrm{Rp}$. 124.900.000,- sedangkan menggunakan metode stepping stone menghasilkan biaya optimum sebesar Rp. 123.700.000,-

2. Program perhitungan distribusi produk Galeri Bimasakti berbasis desktop dapat melakukan pengolahan data sesuai dengan perhitungan manual.

3. Penelitian ini dapat dikembangkan lebih baik lagi dengan mengembangkan program berbasis web. Selain itu sumber tujuan tidak dibatasi dua lokasi saja.

\section{DAFTAR PUSTAKA}

DURAPHE, S. S., 2017. A New Method For The Optimum Solution of A Transportation Problem. International Journal of Mathematics and Application, 5(3-C), pp. 309-312.

FAHMI, F., 2017. Penerapan Metode Stepping Stone Untuk Transportasi Pengiriman Barang Pada CV Mitra Logistics. Majalah INTI, Volume 12.

IRWAN, H. \& YUNIRAL， 2016. Optimasi Penjadwalan Produksi Dengan Metode Transportasi. PROFISIENSI, Volume 04, pp. 79-89.

ISWANTI, N., HASIBUAN, N. A. \& MESRAN, 2016. Aplikasi Transportasi Pengiriman Barang Menggunakan Metode Least Cost dan Modified Distribution Pada CV Nihta Cargo Express. Jurnal riset Komputer (JURIKOM), Desember, Volume 3, pp. 106 - 110.

MULYONO, S., 2002. Riset Operasi. Jakarta: Fakultas Ekonomi Universitas Indonesia.

PATEL, U. D., PATEL, D. H. \& BHAVSAR, R. C., 2017. Transportation Problem Using Stepping Stone Method And Its Applications. International Journal of Advanced Research in Electronics and Instrumentation Engineering, 6(1).
RANGKUTI, A., 2013. Riset Operasi dan Aplikasinya. Surabaya: Brillian Internasional.

ROSTA, J. \& TANNADY, H., 2012. Pendistribusi Produk yang Optimal Dengan Metode Transportasi. Jurnal Teknik dan Ilmu Komputer, Oktober - Desember .Volume 01.

SISWANTO, 2007. Operations Research. Jakarta: Erlangga.

SUSANTA, B., 2010. Program Linear. Yogyakarta: Departemen Pendidikan dan Kebudayaan.

TAHA, H. A., 2004. Riset Operasi Jilid 1. Jakarta: Binarupa Aksara.

TAMIN, O., 2000. Perencanaan dan Pemodelan Transportasi, Edisi Kedua. Bandung: ITB. 
Halaman ini sengaja dikosongkan 